\title{
An Overview on Polymer Retention in Porous Media
}

\author{
Sameer Al-Hajri *(D), Syed M. Mahmood * ${ }^{(\mathbb{D}}$, Hesham Abdulelah $\left(\mathbb{D}\right.$ and Saeed Akbari ${ }^{(1)}$ \\ Department of Petroleum Engineering, Universiti Teknologi PETRONAS, Seri Iskandar 32610, Perak, Malaysia; \\ heshamsaif09@gmail.com (H.A.); akbari.sa70@gmail.com (S.A.) \\ * Correspondence: ensamyo87@gmail.com (S.A.-H.); mohammad.mahmood@utp.edu.my (S.M.M.); \\ Tel.: +60-111-667-5972 (S.A.-H.); Tel.: +60-5368-7103 (S.M.M.)
}

Received: 8 September 2018; Accepted: 8 October 2018; Published: 14 October 2018

\begin{abstract}
Polymer flooding is an important enhanced oil recovery technology introduced in field projects since the late 1960s. The key to a successful polymer flood project depends upon proper estimation of polymer retention. The aims of this paper are twofold. First, to show the mechanism of polymer flooding and how this mechanism is affected by polymer retention. Based on the literature, the mobility ratio significantly increases as a result of the interactions between the injected polymer molecules and the reservoir rock. Secondly, to provide a better understanding of the polymer retention, we discussed polymer retention types, mechanisms, factors promoting or inhibiting polymer retention, methods and modeling techniques used for estimating polymer retention.
\end{abstract}

Keywords: polymer flooding; polymer retention; mobility ratio

\section{Introduction}

Implementing enhanced oil recovery (EOR) techniques has become more significant to recover more hydrocarbons, with the continuation of exploration and development of new oil reserves. Vladimir et al. indicated that the lifetime of a reservoir mostly consists of three phases [1]: primary recovery as oil is extracted by naturally driven mechanisms, secondary recovery with reservoir pressure maintaining techniques through water and gas injection, and enhanced oil recovery often called tertiary recovery with a wide range of advanced technologies [2]. In primary recovery and secondary recovery, only $20-40 \%$ of the potential oil can be extracted. It is possible to extract up to $30 \%$ of the original oil reserve in the well by the implementation of EOR techniques [1,3-5].

Furthermore, as of 2017, it has been estimated by the organization of the petroleum exporting countries that approximately 1.5 trillion barrels of proven crude oil remain in reservoirs globally. After the exhaustion of the applications of conventional recovery methods, enhanced oil recovery helps not only extract these reserves but also guarantees a continued supply of oil in the future [6]. EOR mechanisms broadly include chemical flooding, gas injection and thermal recovery. In chemical flooding, some chemicals such as polymers are added to the injected water to enhance the oil displacement ability.

The ability of water to displace oil and increase production was first noticed in the Pithole city area of Pennsylvania in 1865 as an accidental water injection to the hydrocarbon zone [7]. In 1924, petroleum companies realized the problem of insufficient oil recovery by natural energy and the need to sweep more oil from reservoirs, and first five spot pattern water injection was first implemented in Bradford oil field, Pennsylvania [7,8]. More hydrocarbon was extracted using waterflooding techniques. However, in 1949, Muskat first indicated that waterflood performance would be affected by fluid mobility [9], which was an essential discovery that helped other researchers start studying new techniques for improving water mobility. Stiles, Dykstra, and Parsons used permeability and distribution capacity in waterflooding calculations, and the latter two researchers pointed out the effect of the mobility ratio and permeability variation on recovery $[10,11]$. The mobility ratio's effect on water 
encroachment for a specific flood patter was also studied. Moreover, the mobility ratio impacts on injection and production histories in a five-spot waterflood were also investigated [12,13]. Furthermore, Dyes showed the effect of the mobility ratio on the production of oil after a breakthrough [14]. By 1962 Caudle, Witte and Barnes suggested that by increasing water viscosity, waterflood sweep efficiency can be improved $[15,16]$. In 1964, Pye and Sandiford conducted a fruitful study showing that adding a small amount of water-soluble the polymer can efficiently reduce the mobility of water used in waterflooding which in turn will reduce the mobility ratio thus improving sweep of oil $[17,18]$. Since then, studies were directed towards the polymer flooding efficiency, affecting factors, limitations, challenges, measurements and modeling techniques of polymer flooding.

\subsection{Mechanism of Polymer Flooding}

It is not possible for oil and water to completely displace one another in a reservoir as oil and water are immiscible fluid $[19,20]$. Immiscibility of both fluids is reflected in the residual oil saturation and irreducible water in the relative permeability curve. As indicated by Mridul results, for a waterflood system, despite the injected quantity of water into the reservoir, the oil saturation is not reduced below the residual oil saturation [21]. Introducing the injected water with a water-soluble polymer will increase the water viscosity [20,22-27]. Moreover, the effective permeability of water in the swept zone can be reduced depending on the type and concentration of the polymer used [28-30]. Polymer flooding is an enhanced oil recovery process in which a specified polymer concentration (usually 200-1500 ppm) is added to the injected water. Polymer increases the viscosity of the injected solution and therefore preferably decreases the water to oil mobility ratio which results in improving the displacement efficiency of the injected displacing solution [31-33]. Polymer flooding does not significantly improve displacement (microscopic) efficiently because the change in capillary number $\left(\mathrm{N}_{\mathrm{C}}\right)$ is rather small. However, residual oil saturation can be reached more quickly and economically [34].

\subsection{Mobility Ratio}

The mobility ratio concept is widely utilized in literature for describing the displacement process efficiency such as waterflooding displacement efficiency $[7,35,36]$. The mobility ratio provides measurements of the fluid's relative movement for the displacement process. It is defined as the ratio of the mobility of the displacing fluid to the mobility of the displaced fluid [37]. The term mobility of a fluid is a measure of the ratio of the effective permeability of a particular fluid to its viscosity [21]. For a specific flood application, if the mobility ratio is higher than one, the flood is considered unstable, and viscous fingering is expected. In contrast, a flood is deemed to be stable for a mobility ratio of less than one and displacement is efficient [37]. The following equation defines the mobility ratio.

$$
M=\frac{K_{r w}}{\mu_{w}} / \frac{K_{r o}}{\mu_{o}}
$$

It is important to mention here that mobility ratio is calculated before the breakthrough. From the equation $K_{r w}$ is considered the value at average water saturation behind the flood front in the water contacted portion of the reservoir. This means that polymer flooding application is more efficient if started at earlier stages of the reservoir, particularly before breakthrough. However, lots of polymer flood operations are initiated after water breakthrough [7,31]. As a result, to calculate the mobility ratio during polymer flooding, we use the equation:

$$
M_{p o}=\lambda_{r p} / \lambda_{T}=\left(\frac{K_{r p}}{\mu_{p}}\right)\left(\frac{K_{r o}}{\mu_{o}}+\frac{K_{r w}}{\mu_{w}}\right)
$$

which defines the mobility ratio as the relative mobility of the polymer slug $\lambda_{r p}$ to the total relative mobility of the oil water bank $\lambda_{T}$. In order to obtain these values, the relative permeability curves need to be measured on native state cores in the laboratory, whereas, the mobility of the polymer is usually 
determined at the residual oil saturation. Furthermore, just before the breakthrough, the relative mobility of the water $\frac{K_{r w}}{\mu_{w}}$ is assumed to be zero.

During polymer flooding, the direction of the saturation changes. Therefore, the mobility ratio during polymer flooding for the same polymer concentration increases from a low to a maximum value in the medium saturation range [31]. Jewett and Schurz concluded that improvement in oil recovery using polymer flooding is mainly implemented for cases with waterflooding mobility ratio at a range of 1:10, and the oil recovery increment seems to fall off more quickly below a mobility ratio of one rather than a mobility ratio above ten [38].

The idea of using polymer flooding is to use a polymer that functions as a mobility control agent that will provide a better displacement and sweep efficiencies. It is estimated that the efficiency of polymer flood is in the range of $0.7-1.75 \mathrm{lb}$ polymer per bbl of incremental oil production [3]. Therefore, polymer flooding target is the oil saturation above the residual oil saturation [39-41]. Polymer flooding has shown to be successful in a variety of types of reservoirs. Moreover, comparing to other enhanced oil recovery techniques, polymer flooding is simpler and efficient [42,43]. However, there are significant interactions between the injected polymer molecules and the reservoir rock [44-46]. These interactions may cause the polymer to be retained by the reservoir rock and may cause a bank of injection fluid to form wholly or partially denuded of the polymer. The viscosity of this fluid bank will be much lower than the injected polymer solution. Generally, this will reduce the efficiency of the polymer flood [47].

This paper provides an overview of recent advances in polymer retention in porous media. This overview consists of a discussion on polymer retention concept, the three mechanisms of polymer retention, factors influencing polymer retention, methods used to estimate polymer retention and modelling techniques for polymer adsorption. Furthermore, this paper shows the advantages and technical issues of each of the measuring methods. Therefore, this review paper intends to provide a comprehensive reference for researchers investigating polymer retention to enhance the understanding of polymer retention and its relevance to polymer flooding projects.

\section{Polymer Retention}

Polymer retention has a major impact on the rate of polymer propagation through porous media during polymer flooding, and consequently, on oil recovery [48,49]. It has a substantial effect in porous media on the transport and performance of polymer solution [50,51]. Consequently, high polymer retention can dramatically delay oil movement and recovery during polymer flooding. To illustrate this behavior, Green and Willhite (1998) showed a delay factor ranging from very low retention of $10 \mu \mathrm{g} / \mathrm{g}$ to as high as $200 \mu \mathrm{g} / \mathrm{g}$ as shown in Figure 1. For one pore volume, at low retention rates and a polymer concentration of $2000 \mathrm{ppm}$, the delay factor is approximately $0.03(3 \%)$. In the case of moderate polymer retention of $100 \mu \mathrm{g} / \mathrm{g}$ and a polymer concentration of $1500 \mathrm{ppm}$, the delay factor is about $0.35(35 \%)$, which means that $35 \%$ more of the polymer needs to be injected for reaching the targeted formation, compared to the case with no polymer retention. With very high polymer retention of $200 \mu \mathrm{g} / \mathrm{g}$ and above, polymer retention might have a tremendous impact on the rates of oil displacement and the economic feasibility of polymer flooding.

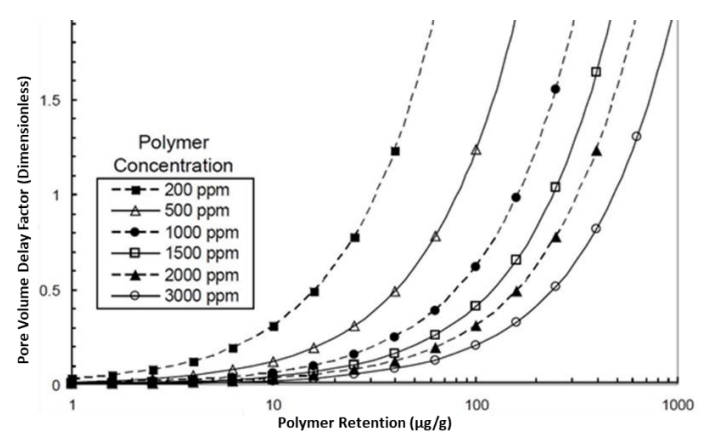

Figure 1. Polymer bank delay factor caused by polymer retention [52]. 
For a successful implementation of polymer flooding, polymer retention must be evaluated before field application. It is vital to understand and predict the influence of retention on the transport of the polymer solution to have a proper design of field scale projects [53]. Polymer retention has been identified as one of the major concerns in the polymer flooding operating process. Polymer retention includes adsorption, mechanical entrapment, and hydrodynamic retention as shown in Figure 2.

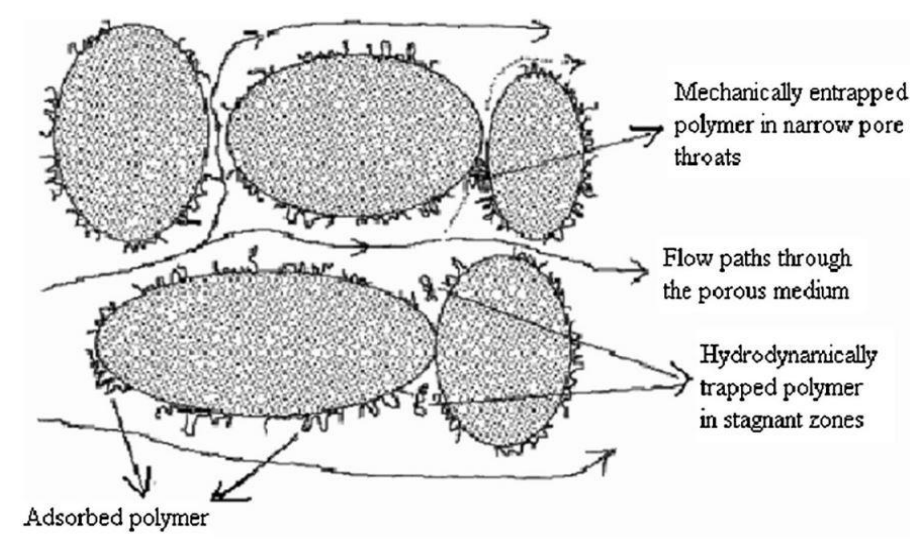

Figure 2. Polymer retention mechanism in porous media [47].

\subsection{Adsorption}

The interaction between the polymer molecules and the solid surface is referred to as adsorption [54]. This interaction makes the molecules of the polymer bind onto the surface of the solid rock largely by physical adsorption (van der Waal's and hydrogen bonding) instead of chemisorption, which means a full chemical bond between the polymer molecules and the solid surface is unlikely to form [47]. Therefore, molecules generally are adsorbed onto the rock surface by the mean of an overall low free energy as shown in Figure 3. The low free energy is formed first by an entropic contribution, as water molecules are released from the polymer solution or rock surface due to polymer adsorption, this, in turn, will cause an increase in entropy [55]. Reduction of the bulk polymer solution concentration by adsorption also increases entropy. In contrast, there is an entropy loss that counters the previous entropy gains, resulting from the loss of the configurational freedom of the polymer when it is adsorbed on the surface [56]. Enthalpy also contributes to the low free energy of polymer adsorption, that occurs for ionic polymers. This contribution is due to polymer electrostatic attraction or repulsion, depending on the surface net ionic charge.

Polymers are characterized by having high molecular weights and long chains; these chains contain many polar groups, which will attach to the available polar points on the rock surface [48]. Essentially, the polymer occupies the adsorption sites at the rock surface, so the larger available surface area to the polymer molecule will have a higher level of adsorption. Adsorption can be severe, as polymer adsorption is irreversible [52,57]. If the adsorbed polymer occupies a large pore volume, it will be difficult to recover a considerable amount of oil. Furthermore, the formation permeability is decreased, leading to a lower recovery factor. 


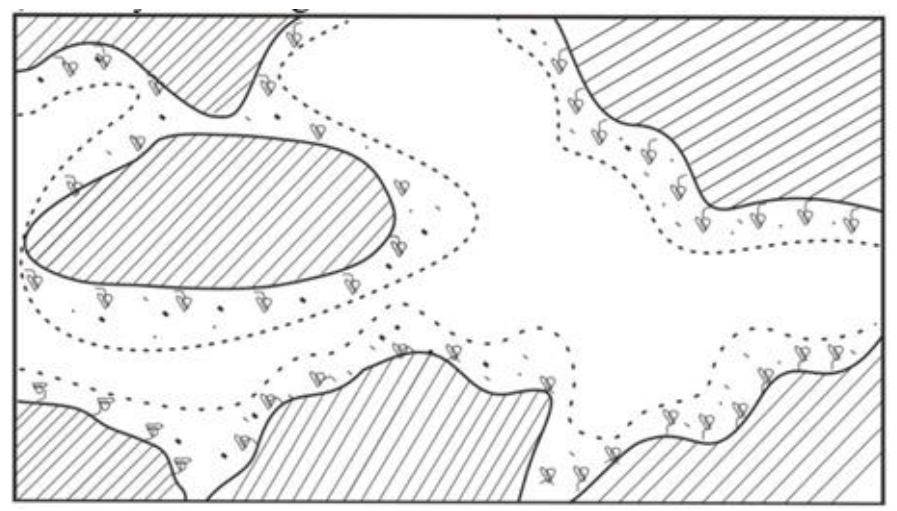

Figure 3. Polymer adsorption in porous media [56].

\subsection{Mechanical Entrapment}

Mechanical entrapment has been studied by several researchers (Gogarty, Smith, Szabo, Dominguez and Willhite) [58-62]. Polymer molecules are relatively large in solution. Entrapment of polymers occurs in porous media as the polymer molecules are large relative to the size of the pores. Several mechanisms contribute to the net effect termed mechanical entrapment. Gogarty visualized mechanical entrapment as an end result of plugged small pores by polymer molecules which are too large to enter them [58]. Water and salt molecules which are considered to be small in size can travel through porous media, but large molecules such as polymer molecules will be trapped and accumulate in these small pores. Gogarty determined that there is an effective polymer molecular size, for hydrolyzed polyacrylamide molecules by filtering 400 ppm of polymer solution through different size of nuclepore filters, Figure 4 shows the effective size ranging between 0.4 and $2 \mu \mathrm{m}$ [58]. Smith's results were somehow similar to Gogarty's results. The effective size of HPAM (Molecular weight $=$ $3 \times 10^{6}$ ) in $0.5 \% \mathrm{NaCl}$ was in the range of 0.3 to $1.0 \mu \mathrm{m}$. According to the literature, some reported that adsorption might be the major dominant for polymer retention in high permeability sands [63]. On the other hand, mechanical entrapment is dominant in low-permeability rock $[60,61,63,64]$. In contrast, Cohen and Christ suggested that for a 5.6 Darcy silica pack, adsorption dominated 35.2\% of the polymer retention, whereas the remainder retention was dominated by mechanical entrapment [65]; this can be as a result of high heterogeneity. It is worth noting that, for better polymer flooding performance most of the current polymer floods are implemented in reservoirs with permeability higher than 0.5 Darcy such as Daqing field with 800 md; Pelican lake: with 1-3 Darcy; Mangala with approximately 5 Darcy; Marmul with 15 Darcy; and Tambaredjo with a range of 4-12 Darcys.

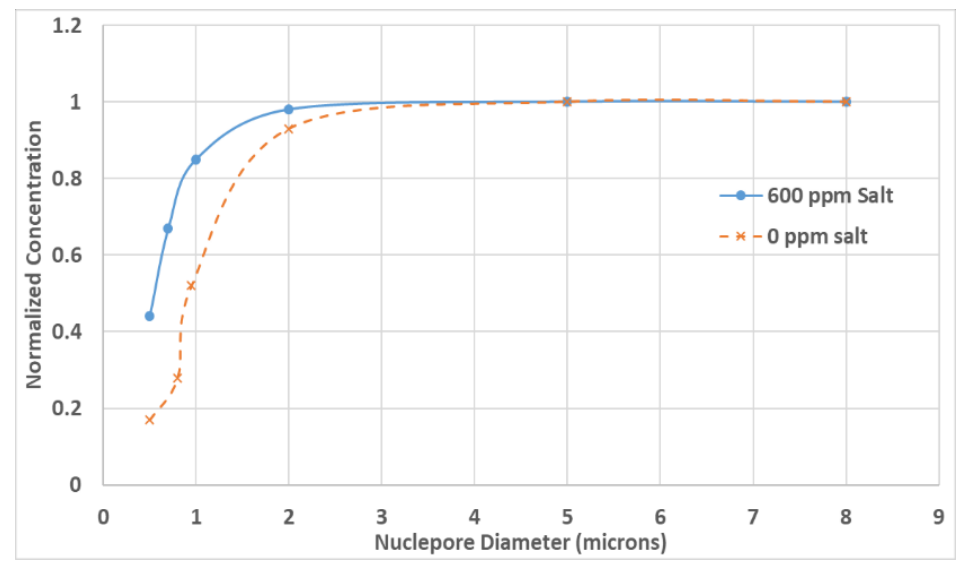

Figure 4. Polymer filteration with different size nuclepore filters [58]. 


\subsection{Hydrodynamic Retention}

Another type of polymer retention is hydrodynamic retention. Chauveteau and Kohler experimentally showed the effect of hydrodynamic retention while running an HPAM core flooding experiment. They noticed that polymer retention changed with the change in flow rates [66]. The idea came after observing that, after reaching steady state in a polymer retention experiment in a core, the retention level changed when a new value of the flow rate was adjusted $[61,66,67]$. In their experiment, as the flow rate increased from 3 cubic meters per day to 10.3 cubic meters per day, more polymer was lost in the porous media from the injected solution, as seen by a dip in the polymer effluent concentration. As the flow rate was lowered again to 3 cubic meters per day, the effluent polymer concentration rose above $400 \mathrm{ppm}$ which was the input value, denoting a drop in the retained level. Hydrodynamic retention of the polymer is the least well defined and understood retention mechanism. The physical picture of the hydrodynamic retention mechanism is thought to be temporarily trapped in stagnant regions by hydrodynamic drag forces called osmotic forces. It may be possible for the polymer concentration in this region to exceed that of the injected fluid. If the flow stops, these polymer molecules may diffuse out of the stagnant region into the main flow channels, so when the flow is retrieved, they are produced as a peak in polymer concentration [47].

\subsection{Inaccessible Pore Volume}

Inaccessible pore volume (IPV) has been widely reported in the literature [61,68-80] as a phenomenon that needs to be considered in polymer flooding applications. When the polymer molecular size is larger than some pores in a porous medium, the polymer molecules cannot flow through those pores. The volume of those pores that cannot be accessed by polymer molecules is called inaccessible pore volume (IPV) $[47,70,81]$. This IPV is occupied by water (brine) that contains no polymer, and this allows polymer concentration to be propagated through porous media more rapidly than water does [70]. IPV depends on the hydrodynamic size of the polymer in the solution, medium permeability, porosity, and pore size distribution and becomes more pronounced as molecular weight increases and the ratio of permeability to porosity (characteristic pore size) decreases. In extreme cases, IPV can be $30 \%$ of the total pore space [73].

\subsection{A Combination of Adsorption and Inaccessible Pore Volume}

As mentioned in the previous section IPV reduces the volume of the porous media that the polymer flows through. Therefore, polymer adsorption can be decreased due to the presence of IPV since less polymer solution will be in contact with the rock surface than total pore volume. Dawson and Lantz (1972) first illustrated the effect of both polymer adsorption and IPV. Figure 5 shows four possible scenarios for this effect as follows:

Scenario A: No retention nor IPV. The polymer will break through at $1 \mathrm{PV}$.

Scenario B: No retention, IPV represents $0.25 \mathrm{PV}$ of the total pore volume. The polymer will break through at $0.75 \mathrm{PV}$.

Scenario C: Retention is $0.25 \mathrm{PV}$ and no IPV. The polymer will break through at $1.25 \mathrm{PV}$.

Scenario D: Retention is $0.2 \mathrm{PV}$, IPV is $0.25 \mathrm{PV}$. The polymer will break through at $0.95 \mathrm{PV}$.

In the case of no retention and no IPV, ideally, we expect the polymer to break out after injecting one PV of the polymer as shown in scenario A. Polymer bank emerges early as shown in scenario B in the case of the inaccessible pore volume and breakout curve will shift forward. On the contrary, the front edge will be affected and break out will be delayed by adsorption. Moreover, the back edge is not affected; hence, the polymer bank becomes smaller as shown in scenario $C$. the combination adsorption and IPV in porous media shifts the polymer bank forward and reduces the amount of the polymer at the effluent as a result of adsorption in the porous media as shown in Figure 2 Scenario D. 


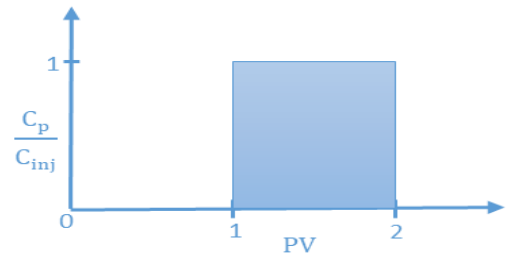

A: No Retention and no IPV

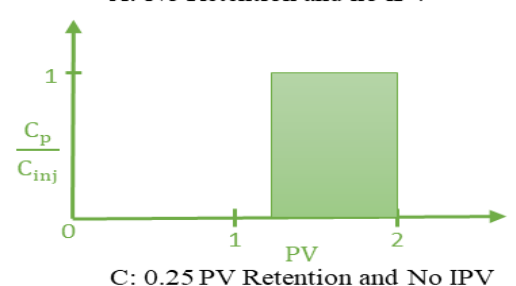

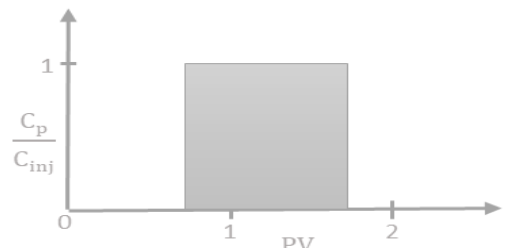

B: No Retention and 0.25 PV IPV

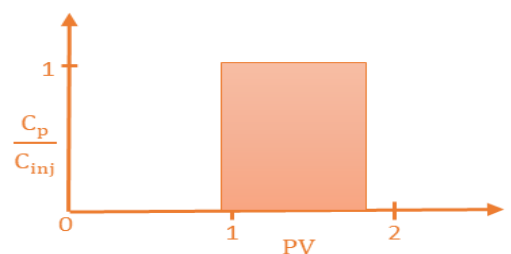

D: 0.25 PV Retention and 0.25 PV IPV

Figure 5. Ideal breakout curves [70].

\subsection{Static Versus Dynamic Retention}

There are large differences between the level of static adsorption of polymers and dynamically retained level in a core or pack [82] as shown in Table 1. These differences are the result of changes in the specific surface area of consolidated and unconsolidated packs and the accessibility of certain portions of the pore space. These differences also depend on the extent of mechanical retention that is present in the dynamic core flood experiment $[81,83]$.

Table 1. Comparison of polymer adsorption in static and dynamic test for three polymers at a polymer concentration of $1500 \mathrm{mg} / \mathrm{L}$.

\begin{tabular}{cccc}
\hline Polymer & FP6040 & DQ3500 & KYPAM-2 \\
\hline \multicolumn{5}{c}{ Static Test } \\
Adsorption amount $\mu \mathrm{g} / \mathrm{g}$ & 1492 & 876 & 1172 \\
Dynamic Test & & 159 \\
\hline \multicolumn{5}{c}{ Adsorption amount $\mu \mathrm{g} / \mathrm{g}$} & 196 & 125 & 159 \\
\hline
\end{tabular}

\section{Factors Effecting Polymer Retention}

\subsection{Polymer Type Effect}

In early studies by Szabo for dynamic polymer adsorption, it was shown that 2-acrylamido2methyl propane sulfonate (AMPS) adsorption is lower than HPAM [60]. Broadly, xanthan adsorption in porous media is much lower than that of HPAM and tends to show less sensitivity to the salinity/hardness conditions of the solvent $[47,52]$. In another study by Szabo, adsorption and retention measurements in Berea cores were carried out on different types of polymers, including AMPS polymers, HPAMs, a xanthan and other polymers. The range of measured retention was lower for the AMPS polymers (35-72 lb/AF) than for the HPAM polymers (88-196 lb/AF) in similar Berea cores ( $\mathrm{k}=0.328-0.679$ Darcy) [60]. Figure 6 shows more adsorption examples for different types of polymers which illustrates the vast variation in adsorption as a function of the type of the polymer. 


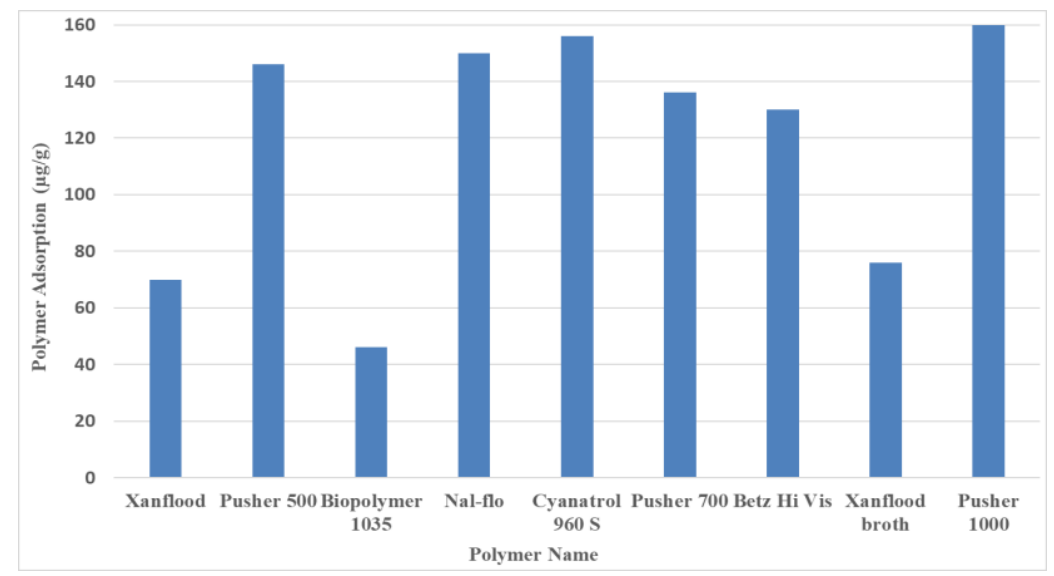

Figure 6. Polymer adsorption for different types of polymers [81].

\subsection{Molecular Weight Effect}

Reported results considering the effect of molecular weight on polymer static adsorption for sulfonated polyacrylamide polymers showed that level of adsorption was increased by increasing molecular weight $[84,85]$. This is in accordance with theory since a polymer with a higher molecular weight would form a thicker layer of the polymer when adsorbed on a surface [84]. In dynamic polymer adsorption studies, sometimes higher levels of adsorption were seen for higher molecular weight polymers, but this adsorption leveled off after a specific value of the molecular weight [86]. However, dynamic adsorption in silica sand decreased with increasing molecular weight, although the effect was not large. Studies on the effect of molecular weight on retention of sulfonated polyacrylamide copolymers studied by Rashidi $(2009,2011)$ led to the conclusion that by increasing the molecular weight of the polymer, less polymer was retained $[83,85]$. The observation was explained by inaccessible pore volume concept; larger polymers are unable to enter the smaller pores of the rock. Lakatos et al. (1979) found that the level of HPAM retention for a 500 ppm solution in the sandpack decreased slightly with increasing molecular mass but decreased even more sharply as the degree of hydrolysis increased [82]. They considered the degree of hydrolysis and the electrolyte concentration to have the most influence on molecular size (coil density) and hence the adsorption level. In this respect, they noted that the role of the molecular mass is very small.

\subsection{Polymer Concentration Effect}

The adsorption amount dependence on the polymer concentration for a typical unhydrolyzed and a partially hydrolyzed polyacrylamide shows similar behavior. Despite the considerable differences in the absolute values, it is characteristic that the adsorption increases with the increase in polymer concentration $[52,79,87]$. Zheng claimed that the Langmuir isotherm was applied to his results. However, he only measured retention for $250 \mathrm{ppm}, 750 \mathrm{ppm}$ and $1500 \mathrm{ppm}$ polymer solutions [87]. Moreover, his results showed that the highest retention was at $1500 \mathrm{ppm}$, that is only less than 1.5 times than that from the $250 \mathrm{ppm}$. Szabo measured retention by injecting polymer solution into a 1.2 Darcy unconsolidated core. Initially, polymer retention was $3.50 \mu \mathrm{g} / \mathrm{g}$ at $300 \mathrm{ppm}$; then by increasing polymer concentration to $600 \mathrm{ppm}$, retention was measured at $6 \mu \mathrm{g} / \mathrm{g}$ [60]. Another retention study by Huang and Sorbie (1993) for Scleroglucan in Bollotini packed columns showed an increase from $8.21 \mu \mathrm{g} / \mathrm{g}$ to $11.71 \mu \mathrm{g} / \mathrm{g}$ as the concentration rose from 50 to $200 \mathrm{ppm}$ [79]. A summary of the results of the polymer concentration effect on adsorption is shown in Table 2. 
Table 2. Polymer retention dependency on polymer concentration.

\begin{tabular}{cccc}
\hline Polymer Concentration $(\mathbf{p p m})$ & Type of Polymer & Retention $(\boldsymbol{\mu g} / \mathbf{g})$ & Reference \\
\hline $10-6000$ & HPAM & $20-420$ & Zhang and Seright (2013) \\
$20-1000$ & HPAM & $21-30$ & Green and Willhite (1988) \\
$250-1500$ & HPAM & $40-58$ & Zheng (2000) \\
$50-200$ & Scleroglucan & $8.2-11.7$ & Huang and Sorbie (1993) \\
\hline
\end{tabular}

Another study by Zhang and Seright (2014) for both static and dynamic retention on the polymer concentration effect on adsorption concluded the overall behavior of concentration dependency. They concluded that different polymer adsorption behavior exists in three regions dilute, semi-dilute and concentrated regions [51]. Polymer adsorption has a small dependency in the dilute and concentrated regions, whereas, polymer adsorption has a high dependency on polymer concentration in the semi-dilute region as shown in Figure 7. This might be a fruitful conclusion for the adsorption dependency on concentration as previous reports showed a very small increase in adsorption for low and high polymer concentration compared to polymer medium concentration between (500-2000) ppm.



Figure 7. Polymer adsorption in different concentration regions [51].

\subsection{Rock Surface Effect}

The iron and clay content of the porous medium has a strong effect on retention. The HPAM adsorption level on calcium carbonate is significantly higher than adsorption on the silica surface [81]. Higher adsorption might be due to the vigorous interactions between the carboxylate groups on the HPAM and the surface $\mathrm{Ca}^{2+}[59,64,82]$. More experimental examples on iron and clay content effect are shown in Table 3.

Table 3. Polymer retention dependency on mineralogy.

\begin{tabular}{cccc}
\hline Mineral & Polymer Type & Retention $(\mu \mathrm{g} / \mathrm{g})$ & Reference \\
\hline Kaolinite & HPAM & $339-1217$ & Meister (1980) [88] \\
Baker dolomite & HPAM & $1.9-17.8$ & Meister $(1980)$ \\
Kaolinite & Xanthan & 16,900 & Hughes (1990) \\
Siderite & Xanthan & 15,600 & Hughes (1990) \\
Montmorillonite & CPAM & 180,000 & Chiappa (1999) \\
Quartzite & CPAM & 610 & Chiappa (1999) \\
Calcium carbonate & HPAM & $20-100$ & Szabo (1975) \\
\hline
\end{tabular}

\subsection{Salinity Effect}

Increasing the salinity concentration generally increases the level of polymer adsorption. Many physical and chemical properties of the injected chemical agents are affected by salinity, 
like viscosity, chemical activity, stability, and adsorption [12]. Charge type (positive, negative, or neutral) of the rock surface is disturbed in the presence of salinity, which leads to different behavior of the rock surface [12]. Smith (1970) showed that a low concentration of calcium ion $\mathrm{Ca}^{2+}$ will promote HPAM adsorption on silica, as the divalent ions compress/squeeze the size of the molecules of the flexible HPAM and reduce the static repulsion between the silica surface and the polymer carboxyl group [59]. Smith results also showed that polymer retention increased from about $11 \mathrm{~g} / \mathrm{m}^{2}$ at $1 \%$ $\mathrm{NaCl}$ to $60 \mathrm{~g} / \mathrm{m}^{2}$ at $10 \% \mathrm{NaCl}$.

\subsection{Hydrolysis Effect}

As the degree of hydrolysis increases, the level of HPAM retention in the sand pack decreases [82]. Adsorption decreases with hydrolysis until adsorption reaches a minimum. Minimum adsorption is because of the charge interaction between the carboxyl group on the polymer (negative charge) and the silica surface on the sand (negative charge). Therefore, an electrostatic repulsion occurs causing a decrease in adsorption.

\subsection{Permeability Effect}

Polymer retention decreases with higher permeability. This is due to mechanical entrapment in a low permeability rock compared to that in a high permeability rock. Moreover, a high clay content in low permeability rocks is also another possible reason for higher retention. Table 4 shows two types of rocks with a high dependency on permeability below 0.2 Darcy.

Table 4. Polymer retention dependency on polymer concentration.

\begin{tabular}{cccc}
\hline $\begin{array}{c}\text { Rock Type and } \\
\text { Permeability }\end{array}$ & Polymer Type & Retention $(\mu \mathrm{g} / \mathrm{g})$ & Reference \\
\hline Vosges sandstone 2100 md & HPAM & 155 & Zaitoun and Kohler (1987) [89] \\
Vosges sandstone 520 md & HPAM & 140 & Zaitoun \& Kohler (1987) \\
Reservoir sandstone 137 md & HPAM & 12 & Vela (1976) \\
Reservoir sandstone 12 md & HPAM & 130 & Vela (1976) \\
\hline
\end{tabular}

\subsection{Wetting Phase Effect}

The wetting phase of the rock also affects polymer retention; in an oil-wet system, polymer retention of polyacrylamide at residual oil saturation will considerably decrease by factors of 2 to 5 compared to the retention if the core is $100 \%$ water-saturated [90]. However, in a water-wet system, the effect of residual oil saturation is less noticeable. For example, the retention with residual oil saturation of 0.2 is almost $7.5 \mu \mathrm{g} / \mathrm{g}$ compared to zero residual oil saturation with a retention of $10 \mu \mathrm{g} / \mathrm{g}$.

\subsection{Temperature Effect}

Adsorption decreases with temperature because of a combined physical and chemical reasons such as electrostatic repulsion, hydrophobicity, van der Waals forces and hydrogen bonds. For nonionic polymers, adsorption is more related to hydrogen bond, whereas adsorption is more related to electrostatic repulsion in ionic polymers. Increasing the temperature facilitates the hydrogen bond to break up, causing a decrease in polymer adsorption. Increasing temperature increases the negative charge on the rock surface, leading to higher electrostatic repulsion, so, the ionic polymer adsorption is reduced [81].

\section{Polymer Retention Measurement}

Many factors need to be considered in polymer retention measurements which makes polymer retention measurement a very long and complicated process. A broad range of methods for calculating polymer retention in porous media was investigated by many researchers. We summarize these methods into three categories. 


\subsection{Static Method}

Generally, static methods are used to measure polymer adsorption to estimate the effect of different parameters on polymer adsorption $[85,91,92]$. In this method, crushed sand is prepared, and a known concentration of polymer is added to the crushed core, then the polymer concentration is measured after separation of the polymer solution from the sand. Knowing the initial mass of the sand, polymer adoption is calculated by dividing the lost mass of the solution by the sand weight as shown in Equation (3).

$$
q=V(\mathrm{Co}-\mathrm{Ce}) / W
$$

where $q$ is the adsorption concentration; $V$ is the volume of the polymer solution; $C o$ is the initial polymer concentration; $\mathrm{Ce}$ is the polymer concentration after the static adsorption.

As mentioned in the static versus dynamic retention section, static and dynamic retention will give different results. Mostly, static results will be higher than dynamic results unless the dominant retention mechanism is the mechanical entrapment in very low permeability cores. The static method relies on only two polymer concentration measurements. Therefore, errors in these measurements have an essential impact on the adsorption value. Moreover, to make the sand, the rock needs to be pulverized, which exposes more surface area and minerals which might not be available in the main rock. One more limitation in using the static test is that the mechanical entrapment cannot be measured.

\subsection{Single Polymer Injection Method}

One of the earliest methods used to estimate polymer retention in porous media was based on the calculation of the remaining polymer concentration in porous media after measuring the effluent polymer $[51,63,93]$.

In this method, the polymer is injected through cores or sand packs along with a tracer. Material balance calculation is performed for the effluent concentration profiles in to determine the retention level as shown in Equation (4).

$$
-\Delta \phi V C+\Delta D V=(1-\phi) \frac{d C s}{d t}+\phi p \frac{d C}{d t}
$$

Polymer retention is calculated from the difference between the area under the curves of the polymer and tracer slug. Moreover, the inaccessible pore volume (IPV) can be estimated by the back edge area between the two curves as shown in Figure 8 [70].

It is difficult to retrieve the polymer from the porous media with the injection of a few pore volumes, thus the amount of the polymer retained in the porous media can be overestimated. Therefore an extended injection of brine to recover the polymer is required [48]. This is a result of the unfavorable displacement. However, it is important to indicate that a very low polymer concentration at the effluent will be associated with polymer detection errors which again will overestimate the amount of the retained polymer.

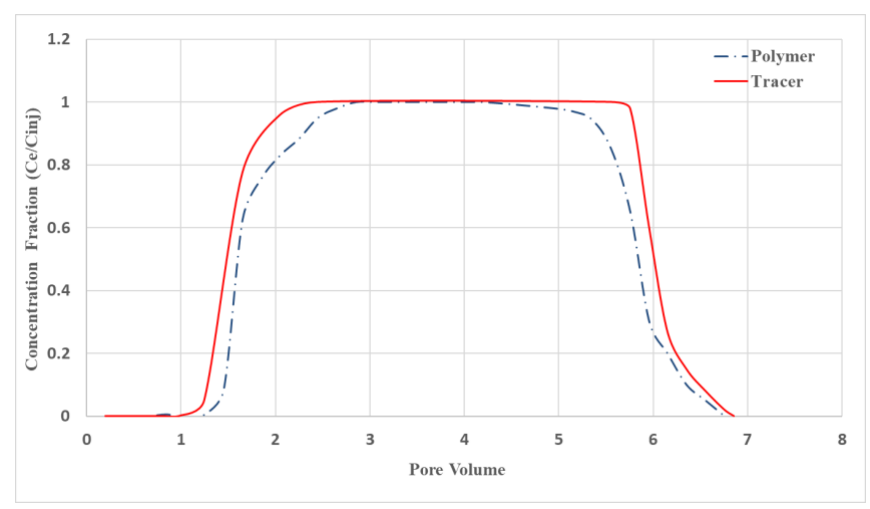

Figure 8. Polymer retention measurement using a single polymer injection method. 


\subsection{Extended Injectivity Method}

This method is the most used method in the literature to determine the polymer retention in porous media $[74,94,95]$. In this method, a polymer solution along with a tracer is injected into the porous media. Injection continues until the polymer and tracer concentrations produced reach the injected polymer and tracer concentrations, followed by extended brine injectivity $(\sim 100)$ pore volumes of brine. The mobile polymer and tracer will be displaced from porous media. Finally, a second bank of polymer and tracer solution is injected. Measurements of polymer retention and IPV (inaccessible pore volume) use only the front part of the break out curves from the two injected slugs, which eliminates the problems associated with the low concentration extended production and viscous fingering. IPV is measured from the area between the second polymer curve and the first/second tracer curve. Polymer retention is measured from the area between the first polymer curve and the second polymer curve as shown in Figure 9.

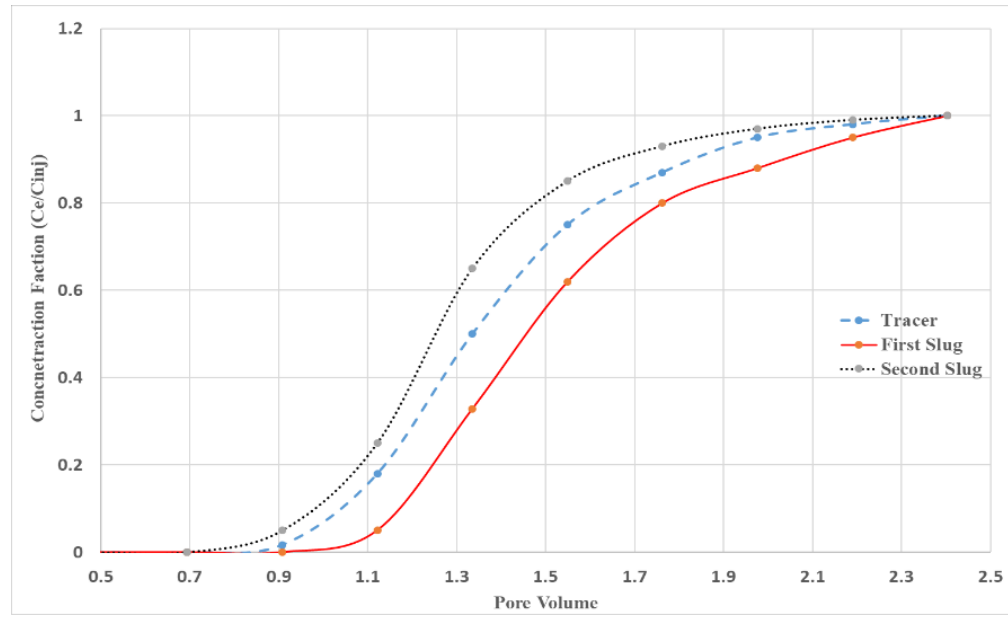

Figure 9. Polymer retention measurement using extended injectivity method.

Equation (5) shows the mathematical expression for polymer retention and IPV calculation.

$$
R=\left\{\left[\sum\left[\left(\frac{C p}{C p o} * \Delta \mathrm{PV}\right)-\left(\frac{C t}{C t o} * \Delta \mathrm{PV}\right)\right]\right]+\mathrm{IPV}\right\} C p o * \frac{P V}{M r}
$$

where $R$ is the polymer retention in porous media; $C p$ and $C p o$ are the produced and injected polymer consecutively; PV is the pore volume in the porous media; $\mathrm{Ct}$ and $\mathrm{Cto}$ are the produced and injected tracer, respectively; IPV is the inaccessible pore volume $M r$ is the mass of the rock.

\subsection{Concentration Profile Method}

Another method used to calculate polymer retention and IPV is by creating the breakout curves in the same manner as in the extended injectivity test for the first and second polymer slug. According to Huh (1990), The dynamic retention can be determined by plotting the effluent profile of a core flood experiment [63]. With regard to the theory of diffuse percolation, when a solution flows through a core at a constant velocity, the point, where the normalized concentration $(\mathrm{Ce} / \mathrm{Cinj})$ on the concentration profile at any time is $0.5[94,96]$. Retention and IPV can be directly measured by reading the values corresponding to the point of normalized concentration at 0.5 as shown in Figure 10. This method is the least used and reported in the literature. However, it showed comparatively identical results with the extended injectivity test. The main advantage of using this method is that IPV can be directly estimated from the cut off value of the normalized concentration at 0.5 from the second polymer slug 
without the need to plot the tracer curve using Equation (6). Retention is estimated from the cut off value of the normalized concentration at 0.5 from the first and second polymer slug using Equation (7).

$$
\begin{gathered}
\mathrm{IPV}=1-\mathrm{PV}_{\text {second slug } \frac{\mathrm{Ce}}{\mathrm{Cinj}}=0.5} \\
\text { Retention }=\mathrm{PV}_{\text {first slug } \frac{\mathrm{Ce}}{\mathrm{Cinj}}=0.5}-\mathrm{PV}_{\text {second slug } \frac{\mathrm{Ce}}{\mathrm{Cinj}}=0.5}
\end{gathered}
$$

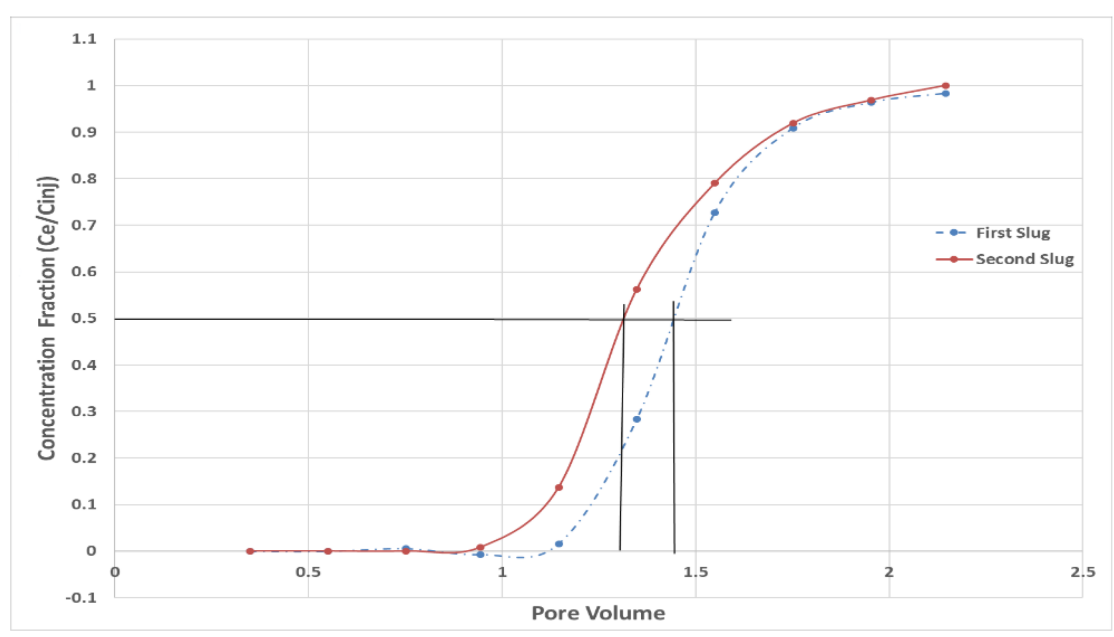

Figure 10. Polymer retention measurement using concentration profile method.

\section{Modeling of Polymer Retention in Porous Media}

In polymer flooding, the polymer solution effectively reduces the displacing fluid mobility whereas the effective permeability of the reservoir is reduced by polymer retention [50]. Polymer retention simulation is primarily part of the polymer flood simulation that is extensively based on modeling parameters such as viscosity depending on polymer concentration, polymer solution shear thinning, shear degradation, permeability reduction, and polymer adsorption. Several simulators are being used to model polymer flooding processes such as Eclipse, CMG and UTCHEM. The imposed assumptions for flow equations development are equilibrium thermodynamic except for organic component dissolution and tracers, immobile solid phases, Fickian dispersion, slightly compressible fluids and soil, Darcy's law and ideal mixing [95]. The boundary conditions are no dispersive flux and no flow across the impermeable boundaries. For a component $k$, the continuity of mass in combination with Darcy's law is represented in terms of the overall volume of the component $k$ per unit pore volume as shown in Equation (8).

$$
-\frac{\partial}{\partial t}\left(\varnothing \check{C}_{k} \rho_{k}\right)=\nabla \cdot\left[\sum_{l=1}^{n_{p}} \rho_{k}\left(C_{k l} u_{l}-D_{k l}\right)\right]
$$

where $k$ is the component species index number $(k$ for polymer $=4) ; l$ is the phase index number for water and oil (water $=1$, oil $=2$ ); $O$ is the porosity; $\check{C}_{k}$ represents the overall concentration of the component $k ; \rho_{k}$ is the density of the component $k ; n_{p}$ is the number of the phases; $C_{k l}$ is the component $k$ concentration in phase $l ; u_{l}$ is the phase $l$ darcy velocity; and $D_{k l}$ represents the dispersion tensor.

Polymer retention in porous media results from adsorption of polymer molecules onto solid surfaces and trapping of the polymer within small pores. As mentioned in the previous sections, polymer retention slows the polymer breakout and depletes the polymer slug. To model polymer 
adsorption level, simulators use a Langmuir-type isotherm as shown in Equation (9) which mainly takes into account only the polymer concentration, salinity, and permeability.

$$
\hat{\mathrm{C}} p=\min \left(C p \frac{a p(C p-\hat{\mathrm{C}} p)}{1+b p(C p-\hat{\mathrm{C}} p)}\right)
$$

where $C p$ and $\hat{C} p$ is the injected and adsorbed polymer concentration, respectively. (Cp- $\hat{C} p)$ represents the equilibrium concentration in the rock-polymer system. The minimum adsorption value is taken to ensure that the adsorption is no greater than the total polymer concentration. $a p$ and $b p$ are the fitting parameters. The parameter ap is calculated from Equation (10).

$$
p=\left(a p 1+a p 2 C_{s e p}\right)
$$

where $K_{r e f}$ and $C_{s e p}$ is the reference permeability (at which adsorption parameters input are specified) and effective salinity respectively. The unit for ap is dimensionless. The effective salinity of the polymer adsorption $C_{s e p}$ is defined by Equation (11).

$$
\mathrm{Csep}=\frac{\mathrm{C} 51+(\mathrm{B} p-1) \mathrm{C} 61}{\mathrm{C} 11}
$$

where C51, C61 and C11 are the anion, divalent, and water concentrations in the aqueous phase, respectively. $\beta p$ is the covalent coefficient. It is noteworthy to mention that the Langmuir model is an equilibrium relationship, and its application assumes polymer adsorption is instantaneous and reversible. When polymer adsorption is considered to be irreversible, the Langmuir model cannot be used directly as the polymer concentration is declining [81].

\section{Scope of This Research}

This paper presents a complete review of polymer retention phenomenon with an aim to provide a comprehensive reference for researchers investigating polymer retention and field practitioner designing a polymer slug for their project:

- A discussion on the strength and limitation of polymer flooding and the mechanism of mobility ratio improvement was provided.

- A review of the polymer retention phenomenon, highlighting its importance, was presented.

- The factors influencing polymer adsorption, mechanical entrapment and hydrodynamic retention were identified.

- The commonly used techniques for polymer retention measurements and their cons and pros viz'a viz other techniques were discussed.

- The commonly used techniques for modeling were described.

\section{Key Observation}

- The flow of polymer solutions through porous media is a complex phenomenon requiring an understanding of retention, flow capacity alteration, and inaccessible pore volume. Estimation of these factors is important for economic evaluation and slug design for a successful implementation of polymer flooding EOR.

- Polymer retention is caused by adsorption on the surfaces, mechanical entrapment due to narrow passageways in porous media, and hydrodynamic entrapment due to high flow rates.

- The retained polymer reduces the flow area, thus the flow capacity (permeability) of the porous media. The mobility of polymer is therefore reduced by both increased viscosity and reduced flow capacity. 
- Inaccessible pore volume allows the polymer to propagate through porous media more rapidly and reduces the amount of polymer retention.

- Each measurement method has some limitations and cannot be relied upon solely. Therefore, a combination of at least two methods for static and dynamic measurements is often needed.

Author Contributions: Conceptualization, S.A.-H. and S.M.M.; Methodology, S.A.-H.; Software, H.A.; Validation, S.A.-H., S.M.M. and S.A.; Formal Analysis, S.A.-H.; Investigation, S.A.-H.; Resources, S.M.M.; Data Curation, H.A. and S.A.; Writing-Original Draft Preparation, S.A.-H.; Writing-Review \& Editing, S.M.M.; Visualization, S.A.-H.; Supervision, S.M.M.; Project Administration, S.A.-H. and S.M.M.; Funding Acquisition, S.M.M.

Funding: This research was funded by Universiti Teknologi PETRONAS and Yaysan UTP-Fundamental Research Grant (Cost Center 0153AA-E84).

Acknowledgments: The authors wish to thank Universiti Teknologi PETRONAS for providing monetary support and an intellectual platform during this research.

Conflicts of Interest: The authors declare no conflict of interest.

\section{References}

1. Alvarado, V.; Manrique, E. Enhanced oil recovery: An update review. Energies 2010, 3, 1529-1575. [CrossRef]

2. Bilak, R. Enhanced Oil Recovery Methods. U.S. Patent US706,999,0B1, 4 July 2006.

3. Abidin, A.; Puspasari, T.; Nugroho, W.A. Polymers for enhanced oil recovery technology. Procedia Chem. 2012, 4, 11-16. [CrossRef]

4. Gao, C. Experiences of microbial enhanced oil recovery in Chinese oil fields. J. Pet. Sci. Eng. 2018, 166, 55-62. [CrossRef]

5. Gao, C.; Shi, J.; Zhao, F. Successful polymer flooding and surfactant-polymer flooding projects at Shengli Oilfield from 1992 to 2012. J. Pet. Explor. Prod. Technol. 2014, 4, 1-8. [CrossRef]

6. Surguchev, L.; Manrique, E.; Alvarado, V. Improved oil recovery: Status and opportunities. In Proceedings of the 18th World Petroleum Congress, Johannesburg, South Africa, 25-29 September 2005.

7. Craig, F.F., Jr. The Reservoir Engineering Aspects of Waterflooding; H.L. Doherty Memorial Fund of AIME: New York, NY, USA, 1971.

8. Fettke, C.R. The Bradford oil field Pennsylvania and New York; Department of Internal Affairs, Topographic and Geologic Survey: Harrisburg, PA, USA, 1938.

9. Muskat, M. Physical Principles of Oil Production; McGraw-Hill Book Co.: New York, NY, USA, 1981.

10. Stiles, W.E. Use of permeability distribution in water flood calculations. J. Pet. Technol. 1949, 1, 9-13. [CrossRef]

11. Johnson, C.E., Jr. Prediction of oil recovery by waterflood-A simplified graphical treatment of the Dykstra-Parsons method. J. Pet. Technol. 1956, 8. [CrossRef]

12. Aronofsky, J.S. Mobility ratio-Its influence on flood patterns during water encroachment. J. Pet. Technol. 1952, 4, 15-24. [CrossRef]

13. Aronofsky, J.; Ramey, H.J., Jr. Mobility ratio-Its influence on injection or production histories in five-spot water flood. J. Pet. Technol. 1956, 8, 205-210. [CrossRef]

14. Dyes, A.; Caudle, B.; Erickson, R. Oil production after breakthrough as influenced by mobility ratio. J. Pet. Technol. 1954, 6, 27-32. [CrossRef]

15. Caudle, B.H.; Witte, M.D. Production potential changes during sweep-out in a five-spot system. J. Pet. Technol. 1959, 12. [CrossRef]

16. Barnes, A.L. The use of a viscous slug to improve waterflood efficiency in a reservoir partially invaded by bottom water. J. Pet. Technol. 1962, 14. [CrossRef]

17. Pye, D.J. Improved secondary recovery by control of water mobility. J. Pet. Technol. 1964, 16, 911-916. [CrossRef]

18. Sandiford, B.B. Laboratory and field studies of water floods using polymer solutions to increase oil recoveries. J. Pet. Technol. 1964, 16, 917-922. [CrossRef]

19. Chaudhuri, A.; Vishnudas, R. A systematic numerical modeling study of various polymer injection conditions on immiscible and miscible viscous fingering and oil recovery in a five-spot setup. Fuel 2018, 232, 431-443. [CrossRef] 
20. Lake, L.W.; Johns, R.; Rossen, B.; Pope, G. Fundamentals of enhanced oil recovery. In Enhanced Oil Recovery; Society of Petroleum Engineers: Richardson, TX, USA, 2014.

21. Kumar, M.; Hoang, V.T.; Satik, C.; Rojas, D.H. High-Mobility-Ratio waterflood performance prediction: Challenges and new insights. SPE Reserv. Eval. Eng. 2008, 11. [CrossRef]

22. Amirian, E.; Dejam, M.; Chen, Z. Performance forecasting for polymer flooding in heavy oil reservoirs. Fuel 2018, 216, 83-100. [CrossRef]

23. Salehi, M.M.; Hekmatzadeh, A.; Sajjadian, V.A.; Masoumi, M. Simulation of polymer flooding in one of the Iranian oil fields. Egypt. J. Pet. 2017, 26, 325-330. [CrossRef]

24. Morelato, P.; Rodrigues, L.; Romero, O.J. Effect of polymer injection on the mobility ratio and oil recovery. In Proceedings of the SPE Heavy Oil Conference and Exhibition, Kuwait City, Kuwait, 12-14 December 2011.

25. Akbari, S.; Mahmood, S.M.; Tan, I.M.; Ghaedi, H.; Ling, L. Assessment of polyacrylamide based co-polymers enhanced by functional group modifications with regards to salinity and hardness. Polymers 2017, 9, 647. [CrossRef]

26. Akbari, S.; Mahmood, S.M.; Tan, I.M.; Ling, O.L.; Ghaedi, H. Effect of aging, antioxidant, and mono- and divalent ions at high temperature on the rheology of new polyacrylamide-based co-polymers. Polymers 2017, 9, 480. [CrossRef]

27. Akbari, S.; Mahmood, S.M.; Tan, I.M.; Bharadwaj, A.M.; Hematpour, H. Experimental investigation of the effect of different process variables on the viscosity of sulfonated polyacrylamide copolymers. J. Pet. Explor. Prod. Technol. 2017, 7, 87-101. [CrossRef]

28. Ogunberu, A.L.; Asghari, K. Water Permeability reduction under flow-induced polymer adsorption. In Proceedings of the SPE Annual Technical Conference and Exhibition, Houston, TX, USA, 26-29 September 2004.

29. Barreau, P.; Bertin, H.; Lasseux, D.; Glénat, P.; Zaitoun, A. Water control in producing wells: Influence of an adsorbed-polymer layer on relative permeabilities and capillary pressure. SPE Reserv. Eval. Eng. 1997, 12. [CrossRef]

30. Chauveteau, G.; Denys, K.; Zaitoun, A. New insight on polymer adsorption under high flow rates. In Proceedings of the SPE/DOE Improved Oil Recovery Symposium, Tulsa, OK, USA, 13-17 April 2002.

31. Chang, H.L. Polymer flooding technology yesterday, today, and tomorrow. J. Pet. Technol. 1978, 30. [CrossRef]

32. Wang, D.; Cheng, J.; Yang, Q.; Wenchao, G.; Qun, L.; Chen, F. Viscous-Elastic polymer can increase microscale displacement efficiency in cores. In Proceedings of the SPE annual technical conference and exhibition, Dallas, TX, USA, 1-4 October 2000.

33. Wang, D.; Cheng, J.; Xia, H.; Li, Q.; Shi, J. Viscous-Elastic fluids can mobilize oil remaining after water-flood by force parallel to the oil-water interface. In Proceedings of the SPE Asia Pacific Improved Oil Recovery Conference, Kuala Lumpur, Malaysia, 6-9 October 2001.

34. Needham, R.B.; Doe, P.H. Polymer flooding review. J. Pet. Technol. 1987, 39, 1503-1507. [CrossRef]

35. Dake, L. Fundamentals of Petroleum Engineering; Elsivier Science B.V.: Amsterdam, The Netherlands, 1978.

36. Willhite, G.P. Waterflooding; Society of Petroleum Engineers: Richardson, TX, USA, 1986.

37. Wang, Y.; Kovscek, A.R.; Brigham, W.E. Effect of mobility ratio on pattern behavior of a homogeneous porous medium. In Situ 1999, 23, 1-20.

38. Jewett, R.L.; Schurz, G.F. Polymer flooding-A current appraisal. J. Pet. Technol. 1970, 22. [CrossRef]

39. He, J. An Innovative Closed Fracture Acidizing Technique for Deep Carbonate Reservoirs Using GLDA. Ph.D. Thesis, Texas A\&M University, College Station, TX, USA, 2015.

40. Maxey, J.E.; Van Zanten, R. Novel method to characterize formation damage caused by polymers. In Proceedings of the SPE International Symposium and Exhibition on Formation Damage Control, Lafayette, LA, USA, 15-17 February 2012.

41. He, J.; Arensman, D.; Nasr-El-Din, H. Effectiveness of calcium sulfate scale inhibitors in spent hydrochloric acid/seawater system. J. Pet. Environ. Biotechnol. 2013, 4. [CrossRef]

42. Omar, A.E. Effect of polymer adsorption on mobility ratio. In Proceedings of the Middle East Oil Technical Conference and Exhibition, Manama, Bahrain, 14-17 March 1983.

43. Sheng, J.J.; Leonhardt, B.; Azri, N. Status of polymer-flooding technology. J. Can. Pet. Technol. 2015, 54, 116-126. [CrossRef]

44. Banerjee, S.; Abdulsattar, Z.R.; Agim, K.; Lane, R.H.; Hascakir, B. Mechanism of polymer adsorption on shale surfaces: Effect of polymer type and presence of monovalent and divalent salts. Petroleum 2017, 3, 384-390. [CrossRef] 
45. Cheraghian, G.; Nezhad, S.S.K.; Kamari, M.; Hemmati, M.; Masihi, M.; Bazgir, S. Adsorption polymer on reservoir rock and role of the nanoparticles, clay and $\mathrm{SiO}_{2}$. Int. Nano Lett. 2014, 4, 114. [CrossRef]

46. AlSofi, A.M.; Wang, J.; Leng, Z.; Abbad, M.; Kaidar, Z.F. Assessment of polymer interactions with carbonate rocks and implications for EOR applications. In Proceedings of the SPE Kingdom of Saudi Arabia Annual Technical Symposium and Exhibition, Dammam, Saudi Arabia, 24-27 April 2017.

47. Sorbie, K.S. Polymer-Improved Oil Recovery; Springer Science \& Business Media: Berlin/Heidelberg, Germany, 2013.

48. Manichand, R.N.; Seright, R. Field vs. laboratory polymer-retention values for a polymer flood in the tambaredjo field. SPE Reserv. Eval. Eng. 2014, 17. [CrossRef]

49. Zhao, J.; Fan, H.; You, Q.; Jia, Y. Distribution and presence of polymers in porous media. Energies 2017, 10, 2118. [CrossRef]

50. Lee, K.S. Simulation of polymer flood processes in heterogeneous layered systems with crossflow and adsorption. J. Jpn. Pet. Inst. 2009, 52, 190-197. [CrossRef]

51. Zhang, G.; Seright, R. Effect of concentration on HPAM retention in porous media. SPE J. 2014, 19, 373-380. [CrossRef]

52. Green, D.W.; Willhite, G.P. Enhanced Oil Recovery; Society of Petroleum Engineers: Richardson, TX, USA, 1998.

53. Choi, B.; Yu, K.; Lee, K.S. Modelling of polymer retention during low concentrated HPAM polymer flooding in the heterogeneous reservoirs. Int. J. Oil Gas Coal Technol. 2016, 11, 249-263. [CrossRef]

54. Theng, B.K.G. Chapter 2: Polymer Behaviour at Clay and Solid Surfaces. In Developments in Soil Science, Formation and Properties of Clay-Polymer Complexes; Elsivier Science B.V.: Amsterdam, The Netherlands, 1979.

55. Kolodziej, E.J. Transport mechanisms of Xanthan biopolymer solutions in porous media. In Proceedings of the SPE Annual Technical Conference and Exhibition, Houston, TX, USA, 2-5 October 1988.

56. Dang, T.Q.C.; Chen, Z.; Nguyen, T.B.N.; Bae, W. Investigation of isotherm polymer adsorption in porous media. Pet. Sci. Technol. 2014, 32, 1626-1640. [CrossRef]

57. Lee, J.-J.; Fuller, G.G. Adsorption and desorption of flexible polymer chains in flowing systems. J. Colloid Interface Sci. 1985, 103, 569-577. [CrossRef]

58. Gogarty, W.B. Mobility control with polymer solutions. Soc. Pet. Eng. J. 1967, 7, 161-173. [CrossRef]

59. Smith, F.W. The behavior of partially hydrolyzed polyacrylamide solutions in porous media. J. Pet. Technol. 1970, 22, 148-156. [CrossRef]

60. Szabo, M.T. Some aspects of polymer retention in porous media using a C14-tagged hydrolyzed polyacrylamide. Soc. Pet. Eng. J. 1975, 15, 323-337. [CrossRef]

61. Dominguez, J.G.; Willhite, G.P. Retention and flow characteristics of polymer solutions in porous media. Soc. Pet. Eng. J. 1977, 17, 111-121. [CrossRef]

62. Zitha, P.L.J.; Botermans, C.W. Bridging-Adsorption of flexible polymers in low permeability porous media. SPE Prod. Facil. 1998, 13. [CrossRef]

63. Huh, C.; Lange, E.A.; Cannella, W.J. Polymer retention in porous media. In Proceedings of the SPE/DOE Enhanced Oil Recovery Symposium, Tulsa, OK, USA, 22-25 April 1990.

64. Szabo, M.T. An evaluation of water-soluble polymers for secondary oil recovery-Parts 1 and 2. J. Pet. Technol. 1979, 31, 553-570. [CrossRef]

65. Cohen, Y.; Christ, F.R. Polymer retention and adsorption in the flow of polymer solutions through porous media. SPE Reserv. Eng. 1986, 1, 113-118. [CrossRef]

66. Chauveteau, G.; Kohler, N. Polymer flooding: The essential elements for laboratory evaluation. In Proceedings of the SPE Improved Oil Recovery Symposium, Tulsa, OK, USA, 22-24 April 1974.

67. Marker, J.M. Dependence of polymer retention on flow rate. J. Pet. Technol. 1973, 25, 1307-1308. [CrossRef]

68. Shah, B.N.; Lawrence, G.; Willhite, P.; Green, D.W. The effect of inaccessible pore volume on the flow of polymer and solvent through porous media. In Proceedings of the SPE Annual Fall Technical Conference and Exhibition, Houston, TX, USA, 1-3 October 1978.

69. Zampieri, M.F. Evaluation of Polymer Flooding through Small Scale Simulation Models for Enhanced Oil Recovery. Ph.D. Thesis, State University of Campinas, Campinas, Brazil, 2017. (In Portuguese)

70. Dawson, R.; Lantz, R.B. Inaccessible pore volume in polymer flooding. Soc. Pet. Eng. J. 1972, 12, 448-452. [CrossRef]

71. Vela, S.; Peaceman, D.W.; Sandvik, E.I. Evaluation of polymer flooding in a layered reservoir with crossflow, retention, and degradation. Soc. Pet. Eng. J. 1976, 16, 82-96. [CrossRef] 
72. Dabbous, M.K. Displacement of polymers in waterflooded porous media and its effects on a subsequent micellar flood. Soc. Pet. Eng. J. 1977, 17, 358-368. [CrossRef]

73. Pancharoen, M.; Thiele, M.R.; Kovscek, A.R. Inaccessible pore volume of associative polymer floods. In Proceedings of the SPE Improved Oil Recovery Symposium, Tulsa, OK, USA, 24-28 April 2010.

74. Osterloh, W.T.; Law, E.J. Polymer transport and rheological properties for polymer flooding in the north sea. In Proceedings of the SPE/DOE Improved Oil Recovery Symposium, Tulsa, OK, USA, 19-22 April 1998.

75. Hughes, D.S.; Teeuw, D.; Cottrell, C.W.; Tollas, J.M. Appraisal of the use of polymer injection to suppress aquifer influx and to improve volumetric sweep in a viscous oil reservoir. SPE Reserv. Eng. 1990, 5, 33-40. [CrossRef]

76. Gupta, S.P. Micellar flooding the propagation of the polymer mobility buffer bank. Soc. Pet. Eng. J. 1978, 18, 5-12. [CrossRef]

77. Fletcher, A.J.P.; Flew, S.R.G.; Lamb, S.P.; Lund, T.; Bjornestad, E.; Stavland, A.; Gjovikli, N.B. Measurements of polysaccharide polymer properties in porous media. In Proceedings of the SPE International Symposium on Oilfield Chemistry, Anaheim, CA, USA, 20-22 February 1991.

78. Lotsch, T.; Muller, T.; Pusch, G. The effect of inaccessible pore volume on polymer coreflood experiments. In Proceedings of the SPE Oilfield and Geothermal Chemistry Symposium, Phoenix, AZ, USA, 9-11 March 1985.

79. Huang, Y.; Sorbie, K.S. Scleroglucan behavior in flow through porous media: Comparison of adsorption and in-situ rheology with xanthan. In Proceedings of the SPE International Symposium on Oilfield Chemistry, New Orleans, LA, USA, 2-5 March 1993.

80. Liauh, W.C.; Duda, J.L.; Klaus, E.E. An Investigation of the Inaccessible Pore Volume Phenomena. 1979. Available online: https: / /www.onepetro.org/general/SPE-8751-MS (accessed on 1 September 2018).

81. Sheng, J. Modern Chemical Enhanced Oil Recovery: Theory And Practice, 1st ed.; Gulf Professional Publishing: Houston, TX, USA, 2010.

82. Lakatos, I.; Lakatos-Szabó, J.; Tóth, J. Factors influencing polyacrylamide adsorption in porous media and their effect on flow behavior. In Surface Phenomena in Enhanced Oil Recovery; Shah, D.O., Ed.; Springer: Boston, MA, USA, 1981.

83. Rashidi, M.; Blokhus, A.M.; Skauge, A. Viscosity and retention of sulfonated polyacrylamide polymers at high temperature. J. Appl. Polym. Sci. 2011, 119, 3623-3629. [CrossRef]

84. Hlady, V.; Lyklema, J.; Fleer, G.J. Effect of polydispersity on the adsorption of dextran on silver iodide. J. Colloid Interface Sci. 1982, 87, 395-406. [CrossRef]

85. Rashidi, M.; Sandvik, S.; Blokhus, A.; Skauge, A. Static and dynamic adsorption of salt tolerant polymers. In Proceedings of the IOR 2009-15th European Symposium on Improved Oil Recovery, Paris, France, 27-29 April 2009.

86. Gramain, P.; Myard, P. Polyacrylamides with coloured groups for trace analysis in water. Polym. Bull. 1980, 3, 627-631. [CrossRef]

87. Zheng, C.G.; Gall, B.L.; Gao, H.W.; Miller, A.E.; Bryant, R.S. Effects of polymer adsorption and flow behavior on two-phase flow in porous. In Proceedings of the SPE/DOE Improved Oil Recovery Symposium, Tulsa, OK, USA, 19-22 April 1998.

88. Meister, J.J.; Pledger, H., Jr.; Hogen-Esch, T.E.; Butler, G.B. Retention of polyacrylamide by berea sandstone, baker dolomite, and sodium kaolinite during polymer flooding. In Proceedings of the SPE Oilfield and Geothermal Chemistry Symposium, Stanford, CA, USA, 28-30 May 1980.

89. Zaitoun, A.; Kohler, N. The role of adsorption in polymer propagation through reservoir rocks. In Proceedings of the SPE International Symposium on Oilfield Chemistry, San Antonio, TX, USA, 4-6 February 1987.

90. Broseta, D.; Medjahed, F.; Lecourtier, J.; Robin, M. Polymer adsorption/retention in porous media: Effects of core wettability and residual oil. SPE Adv. Technol. Ser. 1995, 3. [CrossRef]

91. Chiappa, L.; Mennella, A.; Lockhart, T.P.; Burrafato, G. Polymer adsorption at the brine/rock interface: The role of electrostatic interactions and wettability. J. Pet. Sci. Eng. 1999, 24, 113-122. [CrossRef]

92. Li, Q.; Pu, W.; Wei, B.; Jin, F.; Li, K. Static adsorption and dynamic retention of an anti-salinity polymer in low permeability sandstone core. J. Appl. Polym. Sci. 2017, 134. [CrossRef]

93. Mezzomo, R.F.; Moczydlower, P.; Sanmartin, A.N.; Araujo, C.H.V. A new approach to the determination of polymer concentration in reservoir rock adsorption tests. In Proceedings of the SPE/DOE Improved Oil Recovery Symposium, Tulsa, OK, USA, 13-17 April 2002. 
94. Li, K.; Jing, X.; He, S.; Wei, B. Static adsorption and retention of viscoelastic surfactant in porous media: EOR implication. Energy Fuels 2016, 30, 9089-9096. [CrossRef]

95. Delshad, M.; Pope, G.A.; Sepehrnoori, K. A compositional simulator for modeling surfactant enhanced aquifer remediation, 1 formulation. J. Contam. Hydrol. 1996, 23, 303-327. [CrossRef]

96. Wang, J.; Lu, H.; Luo, P. Determination of Inaccessible Pore Volume and Retention Pore Volume by the Use of Effluent Concentration Profile Model. 2003. Available online: http:/ /caod.oriprobe.com/articles/6373693/ Determination_of_inaccessible_pore_volume_and_retention_pore_volume_by.htm (accessed on 25 August 2018).

2018 by the authors. Licensee MDPI, Basel, Switzerland. This article is an open access article distributed under the terms and conditions of the Creative Commons Attribution (CC BY) license (http:/ / creativecommons.org/licenses/by/4.0/). 